\title{
Clinico-Epidemiological Profile and Outcome of Snake Bite Cases Admitted in a Tertiary Care Centre in South India
}

\author{
Mangalasundaram Rangaswami1 ${ }^{1}$, Moorthy Anitha², Subramanian Pradeep Kumar ${ }^{3}$, Jaganathan Prasanth4 \\ ${ }^{1}$ Department of General Medicine, Government Vellore Medical College Hospital, Vellore, Tamilnadu, India. \\ 2Department of General Medicine, Government Vellore Medical College Hospital, Vellore, Tamilnadu, India. \\ ${ }^{3}$ Department of General Medicine, Government Vellore Medical College Hospital, Vellore, Tamilnadu, India. \\ ${ }^{4}$ Department of General Medicine, Government Vellore Medical College Hospital, Vellore, Tamilnadu, India.
}

\section{ABSTRACT}

\section{BACKGROUND}

Snake bite is an important life-threatening emergency but often neglected public health problem in India. India being a subtropical country, has been a land of poisonous snakes, especially in Southern India poisonous snakes like Russell's Viper, Cobra, Krait and Saw Scaled Viper are commonly encountered. In India around 50,000 people are dying every year from snake bites. In spite of these, the true scale of mortality and morbidity from snakebite remains uncertain. We wanted to study the pattern of envenomation and dry bite among the snake bite cases admitted in Government Vellore Medical College Hospital for the period Jan 2018Jan 2019, describe the clinicoepidemiological profile and outcome of snake bite cases. We also wanted to evaluate the predictive factors of mortality among snakebite cases admitted in a tertiary care centre in Vellore, South India.

\section{METHODS}

A retrospective descriptive analysis of data extracted from medical records of 522 snakebite cases admitted in the Medical wards and IMCU at Government Vellore Medical College and Hospital, Vellore, Tamil Nadu, during the period extending from January 2018 to January 2019 was done, to describe Clinico -epidemiological profile and management of snake bite cases. We described age/gender distribution, seasonal trends of snake bite cases. We computed proportion of envenomation, dry bite and case fatality rate. Among envenomation we analysed the trends in antisnake venom (ASV) usage and its clinical outcome. Statistical analysis was done using Epi Info - Version 7.2 software.

\section{RESULTS}

Of the total 522 snake bite cases admitted in the hospital during the period from Jan 2018 to Jan. 2019, it was found that the median age of the snake bite victim was 40 years (range 13-76). Snakebite cases were higher among male (56\%), agriculture worker (47\%), rural population (92\%) and during monsoon July-October (65\%). Sixty percent of the bites occurred in ankle and foot. Species of snake was identified in $23(4 \%)$ cases. The proportion of dry bite and envenomation were $46 \%$ and $54 \%$ respectively. Of the envenomation cases $20 \%$ were haemotoxic, $24 \%$ were neurotoxic and $10 \%$ were local envenomation. The median duration of hospital stay among envenomation cases was 4 (range 1-20 ) days and interval between bite and ASV administration was 4 (range 1-48) hours. Sixty cases (13\%) were allergic to ASV. Case fatality was $2.5 \%(13 / 522)$.

\section{CONCLUSIONS}

Effective management of snakebites would include early admission to a hospital, appropriate ASV administration and early identification of the warning signs. Delay in hospitalization is associated with poor prognosis and increased mortality rate due to consumptive coagulopathy, renal failure and respiratory failure.

\author{
Corresponding Author: \\ Dr. Moorthy Anitha, \\ No. 622, New Street, Vellur Village \& Post \\ Santhavasal Via, Polur Taluk, \\ Tiruvannamalai-606905 District, \\ Tamilnadu, India. \\ E-mail: dranithamoorthi@gmail.com
}

DOI: $10.14260 / \mathrm{jemds} / 2020 / 231$

Financial or Other Competing Interests: None.

How to Cite This Article:

Rangaswami M, Anitha M, Kumar SP, et al. Clinico-epidemiological profile and outcome of snake bite cases admitted in a tertiary care centre in South India. J. Evolution Med. Dent. Sci. 2020;9(13): 1073-1077 DOI:
Submission 22-01-2020,

Peer Review 06-03-2020,

Acceptance 12-03-2020,

Published 30-03-2020.

\section{KEY WORDS}

Snake Bite, Envenomation, Anti-Snake Venom, Dry Bite 


\section{BACKGROUND}

Snake bite is a common medical emergency and is an occupational hazard, more so in rural India, where agriculture and farming are a major source of employment. Snake bite was included in the list of neglected tropical diseases by World Health Organization in the year 2009 D.A. Warrel et al.(1),(2) It is estimated that globally every year, more than 5 million people are bitten by snakes J. P. Chippaux et $\mathrm{al},(3) \mathrm{A}$. Kasturiratne et al,(4) resulting in approximately 20,000-1, 25,000 deaths D. A. Warrell et al.(5) Over 2,000 species of snakes are known worldwide, of which around 400 are poisonous. These snakes belong to the families Elapidae, Viperidae, Hydrophiidae and Colubridae, Al-Homrany et al.(6) Viper bites are more common than other poisonous snakebites in human beings Basu J et al.(7) Of the different varieties of Vipers, the Russell's viper (Vipera russelli) commonly inhabits the Southern Asian countries and the Russell's viper's bite is regarded as a major threatening occupational hazard for the farming community Halesha B.R et al.(8)

The available data on the epidemiology of snakebite from the Indian subcontinent are sparse, because most of the snake bites occurring illiterate, rural people who use witchcraft and traditional healers. Only the cases of snakebite with severe envenomation reach the healthcare centers in most of the instances. More than 2.5 lakh cases of snake bites are reported every year Sinha K et al.(9) Largest number of deaths reported in India is from Uttar Pradesh (UP), Andhra Pradesh and Bihar Mohapatra B et al.(10) However, the true scale of mortality, acute and chronic morbidity from snakebite remains uncertain Halesha BR et al. Death occurs in these patients due to delay in reaching a hospital within the golden hour, lack of availability of specific treatment or toxicity to anti-venom. It has been recommended that snake-bite should be a notifiable disease in many countries in the South East Asian region Gupta YK et al.(11)

This study was conducted at a Tertiary care centre in Vellore, Tamil Nadu, situated in the western part of Tamilnadu, which encompasses many villages where agriculture is the main occupation. Study was done to determine the clinical profile, complications and outcome of venomous snake-bite cases.

\section{METHODS}

This was a Hospital record based descriptive retrospective, epidemiological study. Study was conducted for a period of one year between January 2018 to January 2019. This study was carried out in the Department of Medicine, in Govt. Vellore Medical College, Vellore, Tamilnadu. Vellore district lies in the Eastern Ghats region adjacent to Palar river basin, at 12.9 degree north, 79.1 degree east, 220 meters above the sea level and has a semi-arid climate. It is situated 84 miles west of the State capital, Chennai. The hospital provides tertiary care to the surrounding rural and urban communities and is the main referral center for snake bite cases in the region.

\section{Sample Population}

All snake bite victims fulfilling inclusion/ exclusion criteria who got admitted in General Medicine wards \& IMCU of Government Vellore Medical College Hospital, Vellore were included during the study period. A total of 522 snake bite victims were studied

\section{Inclusion Criteria}

A. Case with history of snake bite irrespective of the envenomation status.

B. Age above 12 years to 70 years.

C. Patients with one or more symptoms of clinical manifestations of snake bite like local swelling, haemorrhage, blisters formation, vomiting, abdominal pain and regional lymphadenopathy, neurological manifestations.

\section{Exclusion Criteria}

A. Patients with bites other than snake bites

B. Patient with a known history of bleeding disorders, malignancies, neurological disorders, endocrine disorders, underlying renal and liver disorders.

C. Chronic alcoholics

D. Patients on anticoagulant drugs.

\section{Sampling Size and Sample Design}

The records of the 522 snakebite victims who were admitted as in patients in the hospital during the period were obtained from the medical records department. This department uses the ICD-10 system for the Classification of diseases. Out of 522 admitted snakebite 222 were non-poisonous snake bites and 300 were poisonous snakebites. Clinical data including age wise distribution, gender, occupation of the victims, the site of bite, time of bite, location of the bite, Seasonal trends, time between bite and presentation, time between bite and administration of ASV, clinical manifestations, complications and mortality outcomes, were obtained from the case records.

ASV was recommended if one of the following features were observed in patients with history of snake-bite-

1. Local swelling more than half of the bitten limb in absence of tourniquet, rapidly increasing oedema and development of compartmental syndrome.

2. Development of tender enlarged lymph-nodes.

3. Blister formation over involved limb.

4. Spontaneous bleeding from bite site, venous puncture site, haematuria.

5. Positive 20-minute whole blood clotting test.

6. Neurotoxic manifestations like Ptosis, External ophthalmoplegia, weakness of neck muscles and bulbar muscles, blurring of vision, paraesthesia around mouth.

7. Hypotension, shock, arrhythmias.

8. Dark colour urine, oliguria, anuria.

\section{Statistical Analysis}

This is a hospital record-based retrospective, descriptive epidemiological study conducted from January 2018 to 2019. 
The incidence and determinants of snakebite related morbidity with reference to types of envenomation, age, sex, site of bite, clinical manifestations of snakebite, bite to hospital and bite to AVS treatment time, first aid and management of snakebite were investigated during the study. The data was analyzed by Epi info (Version 7.2) software. All results were expressed as percentage.

\section{RESULTS}

Descriptive Epidemiology. Distribution of snakebite cases by different characteristics, Vellore, Tamil Nadu, 2018

\begin{tabular}{|cccccc|}
\hline Characteristics & & $\begin{array}{c}\text { Dry Bite } \\
\text { (n=222) }\end{array}$ & $\begin{array}{c}\text { Envenomation } \\
\text { (n=300) }\end{array}$ & $\begin{array}{c}\text { Total } \\
\text { (n=522) }\end{array}$ & \% \\
Age Group (Years) & 13 то 24 & 38 & 40 & 78 & 14.9 \\
& 25 то 34 & 45 & 59 & 104 & 19.9 \\
& 35 то 44 & 49 & 68 & 117 & 22.4 \\
& 45 то 60 & 69 & 101 & 170 & 32.6 \\
& $>60$ & 21 & 32 & 53 & 10.2 \\
\hline \multicolumn{5}{r}{ Table 1. Age Wise Distribution of Snake Bite Cases } \\
\hline
\end{tabular}
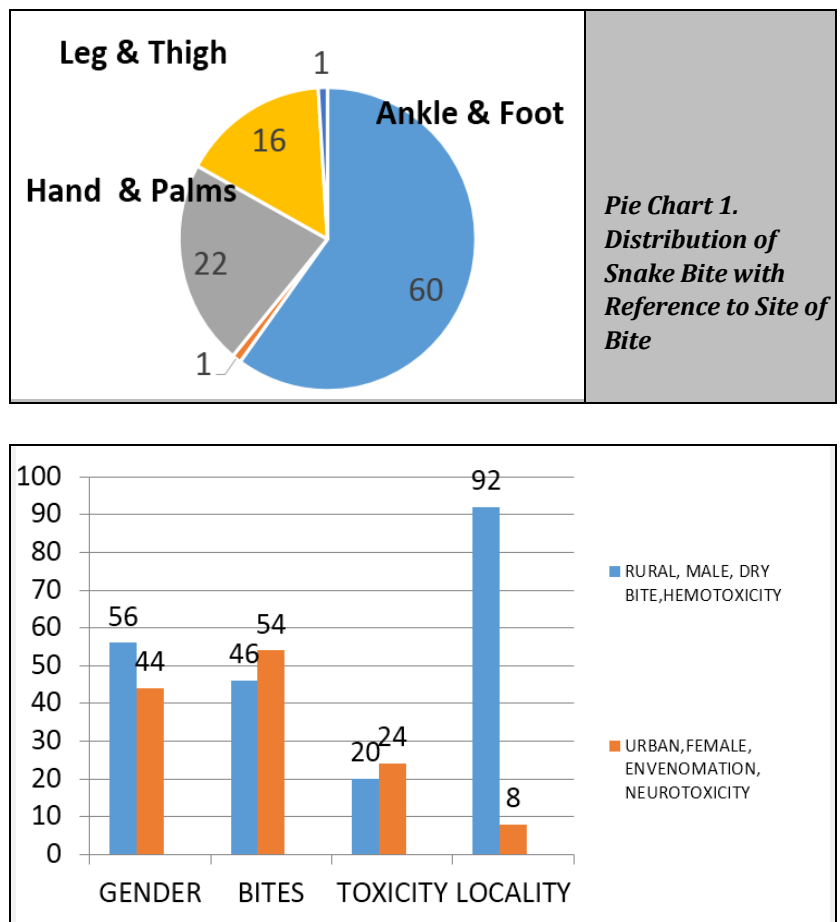

Bar Diagram 1. Distribution of Snake Bites in Relation to Gender Envenomation, and Toxicity \& Locality

\begin{tabular}{|c|c|c|c|c|c|}
\hline \multicolumn{2}{|c|}{ Characteristics } & $\begin{array}{l}\text { Dry Bite } \\
(\mathrm{N}=222)\end{array}$ & $\begin{array}{c}\text { Envenomation } \\
(N=300)\end{array}$ & $\begin{array}{c}\text { Total } \\
(\mathrm{N}=522)\end{array}$ & $\%$ \\
\hline \multirow{6}{*}{ Occupation } & Employed & 27 & 31 & 58 & 11.1 \\
\hline & $\begin{array}{l}\text { Farming \& } \\
\text { agriculture } \\
\text { related }\end{array}$ & 94 & 149 & 243 & 46.6 \\
\hline & Housewife & 59 & 70 & 129 & 24.7 \\
\hline & Self-employed & 3 & 12 & 15 & 2.9 \\
\hline & Student & 36 & 29 & 65 & 12.5 \\
\hline & Unemployed & 3 & 9 & 12 & 2.3 \\
\hline
\end{tabular}

\begin{tabular}{|ccccc|}
\hline Gender & $\begin{array}{c}\text { Sharma } \\
\text { et al }{ }^{(12)}\end{array}$ & $\begin{array}{c}\text { Brunda } \\
\text { et al }\end{array}$ & $\begin{array}{c}\text { Chattopadhyay } \\
\text { et al }\end{array}$ & $\begin{array}{c}\text { Present } \\
\text { Study }\end{array}$ \\
Male & $\mathbf{7 3 \%}$ & $76 \%$ & $60 \%$ & $56 \%$ \\
Female & $27 \%$ & $24 \%$ & $40 \%$ & $44 \%$ \\
\hline \multicolumn{4}{|c|}{ Table 3. Comparing } & Gender Distribution among Other Studies \\
\hline
\end{tabular}

Totally 522 snakebite cases were studied in the period between Jan. 2018.-19. The median age of the snakebite victim was 40 years (range: 13-76). Snakebite cases were higher among Male (56\%), agriculture workers (47\%), rural population (92\%) and during monsoon July- October (65\%). Sixty percent of the bites occurred in Ankle and foot. Species of snake bitten was identified in $23(4 \%)$ cases. The proportion of dry bite and envenomation were $46 \%$ and $54 \%$ respectively. Of the envenomation cases, $20 \%$ were haemotoxic, $24 \%$ were neurotoxic, $10 \%$ were local envenomation. The median duration of hospital stay among envenomation cases was 4 (range: 1-20) days and interval between bite and ASV administration was 4 (range: 1-48) hours. Sixty cases (13\%) were allergic to ASV. Case-fatality rate was $2.5 \%(13 / 522)$. Effective management of snakebites would include appropriate ASV use and predicting alarming signs earlier.

\section{DISCUSSION}

Tamilnadu is one of the states with a high prevalence of snake-bite related morbidities with a CDR of 4.7 per 10,000 patients.(15) Indian reports on the clinical profiles, outcomes and ASV related adverse drug reactions are sparse. In this study, $32.6 \%$ of the patients were in the age group of 45 to 60 years and $56 \%$ were males which was similar to other studies conducted in Karnataka and Andhra Pradesh. This could possibly be due to the social behaviour of men as the dominant earning member of the family mostly working outdoors. Of the patients, $92 \%$ were domiciled in rural areas with a rural: urban ratio of 10.9: 1, similar to other studies conducted in West Bengal and Nellore in Andhra Pradesh. Higher incidence in rural areas can be attributed to agriculture and farming as an occupation, the habit of walking barefoot in the fields and dwelling in thatched and unprotected households. The site of bite was predominantly in the lower limb (59.6\%) while 3 persons had bites in the face.

In the present study, 293 (56\%) patients were male victims, whereas the female victims were 229 (44\%) in number. All the previous reports mention the same findings. Ahuja and Singh(16) in 1954 reported the ratio as 4:1 (M: F). Bhat et al(17) in 1974 reported the incidence as 7:3 (M: F). Among the cases, the number of poisonous bites were 300 and number of non-poisonous bites were 222. Among the male patients, 169 were poisonous, whereas in females, 131 were poisonous snake bites. Among the poisonous snake bites, identification of the exact species of bitten snake ten was possible only in $23(4 \%)$ cases. The proportion of dry bite and envenomation were $46 \%$ and $54 \%$ respectively. Of the envenomation cases, $60(20 \%)$ were haemotoxic. In lower extremities bites are 399 (76.5\%) and in upper extremities 123 (23.6\%). Among them, upper extremity poisonous cases were 228 and lower extremity poisonous cases were 55 . Reid(18) mentions that most of the bites in tropical countries are on lower extremities because the victims are bitten by treading on or near the snake and walking bare foot, while in non-tropical countries most bites are on fingers and hands because the victim deliberately handles the snake. 
In the present study, the day was divided into four groups. Maximum numbers of cases were detected in the interval between 6.00 PM to $12.00 \mathrm{AM}$. The documented figure was 197 among 522 patients. Next on the list was the time interval between $6.00 \mathrm{AM}$ to $12.00 \mathrm{PM}$ where number of patients bitten was 150 . These results are close to studies conducted by Veeramani and Dutt.(19) They have noted $12 \%$ cases bitten during daytime. In the present study, higher incidence was found in Monsoon months. July to October witnessed about $339(65 \%)$ cases of the total snake bites and among them 173 were poisonous bites and 166 were nonpoisonous bites, followed by summer where the total number of snake bites was 90 , among which 80 were poisonous bites and 10 were non-poisonous. Neuroparalytic snake bites were more at the end of summer and beginning of monsoon. Incidence of Vasculotoxic bites was comparatively more in winter. Study conducted by Banerjee 17 (1978) et al noted that incidence of 70-80\% during May to October.

Most human snakebites occur during the monsoon season because of flooding of the habitat of snakes and their prey. It is the life cycle of the natural prey of these reptiles that govern contact with humans. The breeding habits of frogs closely follow the monsoons and rats and mice are always in close proximity to human dwellings. From another south Indian study snakebites are abound during the months of October to December (33\%) and May to July (67\%). In the present study majority of the victims were agricultural workers $(46.6 \%)$ followed by coolie $(24 \%)$.In another study conducted by Amitabha et al majority of the victims were Farmers (42.3\%) followed by coolie workers (17.3\%).

\section{CONCLUSIONS}

The first aid measures recommended is the "DO IT RIGHT" that includes reassurance of snakebite victim, immobilization of the affected limb, immediate referral to hospital and informing the doctor regarding the symptoms. This study highlights the need for early treatment intervention post bite. The rate of recovery was better when the patients were administered anti-snake venom within 1 hour of the bite. Accessibility of Life Support Measures like Ventilators for Respiratory Failure and haemodialysis units for AKI will go a long way in decreasing the morbidity and mortality of the affected victims, as the affected victims are mostly in the younger and middle age group, who are mostly the main bread winners of the family. The time lapse could be attributed to lack of awareness of complications of snake bite, habit of seeking traditional methods of treatment or lack of treatment facilities nearer to home. Imparting health education, awareness about prevention among the public, early identification of warning symptoms and transfer to a tertiary care hospital will help in the prevention of avoidable deaths due to snakebite. Identification of the type of snake is essential to decide on the type of toxicity and method of treatment to be instituted.

\section{ACKNOWLEDGEMENT}

We would like to acknowledge the patients admitted in Govt. Vellore Medical College and Hospital, Vellore, Tamil Nadu during the study period and the Staff of Medical Records Section, Govt. Vellore Medical College, Vellore-11, for the cooperation and the post graduates of the Department of Gen. Medicine, Govt. Vellore Medical College Hospital, Vellore-11, Tamilnadu.

\section{REFERENCES}

[1] Warrell DA. Snake bite. The Lancet 2010;375(9708)7788.

[2] World Health Organization, Neglected tropical diseases. Geneva, Switzerland. [Last accessed on 2013 Jan 7]. http://www.who.int/neglected_diseases/en.

[3] Chippaux JP. Snake-bites: appraisal of the global situation. Bull World Health Organ 1998;76(5)515-24.

[4] Kasturiratne A, Wickremasinghe AR, de Silva N, et al. The global burden of snakebite: a literature analysis and modelling based on regional estimates of envenoming and deaths. PLoS Med 2008;5(11):e218.

[5] Warrell DA. Guidelines for the Management of Snakebites, Regional Office for South-East Asia - Delhi. WHO, 2010: p. 37.

[6] Al-Homrany M. Acute renal failure following snake bites: a case report and review of the literature. Saudi J Kidney Dis Transpl. 1996;7:309-12

[7] Basu J, Majumdar G, Dutta A, et al. Acute renal failure following snake bites (viper). J Assoc Physicians India. 1977; 25:883-90.

[8] Halesha BR, Harshavardhan L, Lokesh AJ, et al. Study on the clinico-epidemiological profile and the outcome of snake bite victims in a tertiary care centre in southern India. Journal of Clinical and Diagnostic Research 2013;7(1):122-6.

[9] Sinha K. Snake bites kill $46 \mathrm{~K}$ in India yearly. Times of India. TNN | Dec 6, 2011.

[10] Mohapatra B, Warrell DA, Suraweera W, et al. Snakebite mortality in India: a nationally representative mortality survey. PLoS Negl Trop Dis 2011;5(4):e1018.

[11] Gupta YK, Peshin SS. Snake Bite in India: current scenario of an old problem. J Clin Toxicol 2014;4(1):182.

[12] Sharma SK, Khanal B, Pokhrel P, et al. Snake bite reapparaisal of the situation in Eastern Nepal. Toxicom 2003;41(3):285-9.

[13] Brunda G, Shashidhar RB. Epidemiological profile of snake bite cases from Andhra Pradesh using immunoanalytical approach. Indian Journal of Med Research 2007;125(5):661-8.

[14] Chattopadhyay MD, Sukul B. A profile of fatal snake bite cases in the Bankura district of West Bengal. Journal of Forensic Leg Med 2011;18(1):18-20.

[15] Vaiyapuri S, Vaiyapuri R, Ashokan R, et al. Snakebite and its socio-economic impact on the rural population of Tamil Nadu, India. PLoS One 2013;8(9):e80090. 
[16] Ahuja MM. Progress in clinical medicine in India. Second Series. 1978: p. 136-77.

[17] Bhat RN. Viperine snake poisoning in Jammu. J Indian Med Assoc 1974;63(12):383-92.
[18] Reid HA, Theakston RD. The management of snake bite. Bull World Health Organization 1983;61(6):885-95.

[19] Virmani SK, Dutt OP. A profile of snake bite poisoning in Jammu region. J Indian Med Assoc 1987;85(5):132-4. 